\title{
A CONCEPÇÃO CARTESIANA DE SUJEITO: A ALMA E O ANIMAL RACIONAL
}

Enéias Forlin*

\section{RESUMO}

A concepção cartesiana de subjetividade é frequentemente mal compreendida. Passados quatros séculos, e depois de milhares de estudos feitos sobre a filosofia de Descartes, ainda se faz uma imagem significativamente distorcida do sujeito cartesiano. Segundo meu ponto de vista, a concepção cartesiana de sujeito é alvo de quatro grandes equívocos de interpretação: o primeiro é que Descartes seria o inventor da distinção real entre a natureza do espírito e da matéria. O segundo é que ele teria feito isso orientando-se por uma intenção primordialmente espiritualista, de ranço teológico e mesmo cristão, de quem pretendia mostrar que a mente ou consciência - sendo de natureza puramente imaterial, feita à imagem e semelhança de Deus - consistia numa realidade mais nobre e elevada que a realidade corpórea. $O$ terceiro é de que a vontade, ou livre arbítrio, seria mesmo a faculdade essencial da alma. Por fim, o quarto é de que a concepção cartesiana de alma ou espírito consiste fundamentalmente na concepção cartesiana de homem ou animal racional. Ora, pretendo mostrar, ao longo de minha exposição sobre a concepção cartesiana de subjetividade, que essas quatro crenças ou opiniões são falsas e, em alguns aspectos, até mesmo contrárias às intenções de Descartes, de modo que são incompatíveis com a concepção cartesiana de sujeito.

Palavras-chave: Alma. Espírito. Intelecto. Vontade. Matéria. Animal racional. Paixões.

\footnotetext{
* Professor do Departamento de Filosofia da Universidade Estadual de Campinas (Unicamp). E-mail: ejforlin@uol.com.br
} 


\section{RÉSUMÉ}

La conception cartésienne de subjectivité est souvent mal comprise. Après quatre siècles et des milliers d'études consacrées à la philosophie de Descartes, on se fait encore une image considérablement déformée du sujet cartésien. D'après moi, la conception cartésienne de sujet est une cible de quatre erreurs d'interprétation: la première est que Descartes serait l'inventeur de la distinction réelle entre la nature de l'esprit et de la matière; la deuxième est qu' il aurait fait cette distinction orienté par une intention avant tout spiritualiste aux relents théologiques et même chrétiens, dont l'objectif serait de montrer que l'esprit ou la conscience - de nature purement immatérielle faite à l'image de Dieu - consistait en une réalité plus noble et élevée que la réalité corporelle; la troisième est que la volonté ou le libre arbitre serait réellement la faculté essentielle de l'âme; et la quatrième est que la conception cartésienne d'âme ou d'esprit consiste fondamentalement en la conception cartésienne d'homme ou d'animal rationnel. Ainsi, je prétends démontrer tout au long de mon exposé sur la conception cartésienne de subjectivité que ces quatre opinions ou croyances sont erronées, voire même dans une certaine mesure contraires aux intentions de Descartes, de telle manière qu'elles sont incompatibles avec la conception cartésienne de sujet.

Mots clé: Âme. Esprit. Intellect. Volonté.Matière. Animal rationnel. Passions.

$$
* * *
$$

Na Meditação Segunda, a partir do parágrafo 5, após ter mostrado que sou na medida em que o penso, Descartes passa a investigar qual é a natureza desse $E u$ cuja existência se põe como necessária pelo próprio ato de pensar. ${ }^{1}$ Não basta saber que minha existência se liga

${ }^{1}$ Méditations - Seconde, A. T., IX., p. 19-20; Meditationes - Secunda, A.T., VII, p. 25. A referência usada para os textos de Descartes é a edição Adam et Tannery 
necessariamente ao ato de pensar, mas é necessário saber agora em que consiste a própria natureza do pensamento: ela está ou não envolvida de alguma maneira com a realidade material corpórea, de modo que, em caso positivo, sua existência implicaria necessariamente a existência do meu corpo.

Descartes começa por reconsiderar o que ele acreditava ser antes da instauração do processo de dúvida hiperbólica exposto na Meditação Primeira. Ora, ele julgava ser provido de um corpo e de uma alma: de um corpo, cuja natureza ele julgava conhecer claramente; e de uma alma, cuja natureza íntima ele não compreendia muito bem, mas cuja existência ele inferia claramente, como unida ao seu corpo, por perceber que este, embora fosse essencialmente passivo, manifestava, no entanto, o poder de mover-se, de alimentar-se, de sentir e de pensar coisas que não se concebia que o puro corpo pudesse fazer por si mesmo.

Na sequência, então, Descartes passa a comparar o que dessa crença anterior ele ainda pode sustentar agora que duvida da existência de qualquer coisa material e, ainda assim, porém, não é capaz negar que existe na medida em que pensa.

Ele reconhece ser agora evidente que a natureza corpórea não é essencial a esse Eu que se põe necessariamente pelo simples ato de pensar.

E quanto à natureza da alma, ela é essencial? Ora, conclui Descartes, se não tenho um corpo material, tampouco preciso de um princípio anímico para organizar a matéria num organismo capaz de locomover-se, de se alimentar e de ter sensações.

Todavia, o que dizer do princípio racional da alma - o espírito pelo qual ela pensa? Posso separar isso do meu ser cuja existência se põe necessariamente pelo simples ato de pensar? Certamente que não! E assim

(Oeuvres de Descartes, publiées par Charles Adam et Paul Tannery, 11 volumes, Paris, Vrin, 1996). Na notação simplificada usada internacionalmente, AT indica a edição; os numerais romanos, o volume; e os algarismos arábicos, o número da página. 
Descartes se vê forçado a concluir que o pensamento é o único "atributo que me pertence e só ele não pode se separado de mim."

"Eu sou, eu existo: isto é certo; mas por quanto tempo? A saber, pelo exato tempo em que penso; pois poderia, talvez, ocorrer que, se eu deixasse de pensar, deixaria, ao mesmo tempo, de ser ou de existir". ${ }^{2}$ Portanto, "Eu sou, eu existo enquanto pensamento". O pensamento que duvida da existência de todas as coisas e, por isso mesmo, não pode atribuir-se a coisa alguma, não pode, entretanto, duvidar de sua própria existência na medida em que pensa e, por isso mesmo, descobre-se como atributo de si próprio e, portanto, como sendo ele a própria coisa de que é atributo, isto é, o pensamento percebe-se como subsistindo em si mesmo, como sendo ele próprio suporte do seu ser, como sendo, portanto, substância (res).

Notemos que toda essa operação conceitual que Descartes realiza na Meditação Segunda, mostra, por um lado, tal como a tradição aristotélico-tomista, que o pensamento é de natureza imaterial, nãoextensiva, puramente inteligível. O pensamento é aquilo que a tradição costuma chamar de alma. E até aqui, apesar das opiniões contrárias, Descartes não está introduzindo nenhuma novidade.

Desde Platão, pelo menos, a alma era considerada de natureza inteiramente distinta da matéria, que provinha do mundo das formas puras e, depois, sobrevivia à realidade material do corpo a que estava unida quando este se corrompia. ${ }^{3}$ Aristóteles, por sua vez, jamais recusou essa natureza puramente imaterial das formas, quando negou o mundo de formas puras e as encarnou na matéria. Tudo o que Aristóteles recusava era a

\footnotetext{
${ }^{2}$ Ibid., ibidem.

${ }^{3}$ Ver Timeo e também o livro V da República. Ver também : ROBIN, L. La pensée grécque. Paris: Ed. Albin Michel, 1948, p. 255-260.
} 
independência das formas inteligíveis com relação à matéria, sua autonomia ontológica como substância. Todavia, ainda assim, ele via na forma e na matéria duas naturezas completamente distintas e irredutíveis uma à outra. ${ }^{4} \mathrm{Na}$ Idade Média, a apropriação que a filosofia cristã fez da filosofia aristotélica só fez acentuar essa distinção radical entre essas duas naturezas - forma e matéria. Para Tomás de Aquino, a alma racional é a única que, além da existência na natureza juntamente com o corpo, sobrevive a este e continua existindo após a sua morte, num além-mundo, de ordem puramente espiritual. Aqui se nota a influência platônica na concepção tomista. Embora Aristóteles parecesse admitir, por um lado, que a alma racional não pereceria juntamente com a destruição do corpo, mas apenas as suas funções vegetativas e sensitivas, por outro lado, ele não podia conceber a existência separada da alma num além-mundo, já que não havia outro mundo para Aristóteles (sendo que a própria natureza é eterna no seu processo de geração e corrupção). Neste caso, a concepção platônica de que a alma sobrevive ao corpo e retorna ao mundo inteligível das Formas, do qual ela própria já participava na sua origem e por sua própria natureza, serviu melhor aos propósitos tomistas de conformar as verdades cristãs à filosofia. ${ }^{5}$

Até aqui, portanto, insisto, Descartes, contrariamente ao que se costuma acreditar, apenas segue a tradição hegemônica na filosofia. A diferença é que ele, se por um lado como que herda esse dualismo ontológico da tradição, por outro lado, demonstra ao mesmo tempo, e agora contrariamente a essa mesma tradição aristotélico-tomista, que a alma, não é, todavia, aquilo que se convencionou chamar de forma, isto é, um princípio inteligível que organizaria a matéria num corpo e que seria responsável pela manutenção e desenvolvimento deste. Não: a alma é apenas pensamento e, como tal, em nada contribui para a organização e manutenção do corpo (e nem este, por sua vez, precisa da

\footnotetext{
${ }^{4}$ Cf. De Anima. Ver também livro VII da Metafísica.

${ }^{5}$ Ver, por exemplo, Compêndio de Teologia, Livro I, Primeira Parte.
} 
alma para existir e se desenvolver enquanto tal). Quer dizer, alma enquanto natureza puramente inteligível, não é uma natureza incompleta, que precisaria para existir de uma natureza distinta, a saber, a matéria, natureza também incompleta, da qual ela seria necessariamente a forma. Nada disso! A alma é uma coisa completa, uma res, uma autêntica substância dotada de autonomia frente à matéria, que não depende do concurso dela para existir.

A contrapartida dessa demonstração da natureza da alma, qual seja, a de que a natureza do corpo é puramente extensiva, e de que ele não precisa de uma alma para organizá-lo e mantê-lo enquanto tal, enfim, de que o corpo é também ele uma coisa completa, uma res, uma autêntica substância dotada de autonomia frente à alma, que não depende do concurso dela para existir, isso só será efetivamente demonstrado na Sexta Meditação depois que Descartes tiver validado o conceito de extensão como uma essência real e imutável (o que ocorre apenas na Quinta Meditação e, além disso, pressupõe a prova da existência de Deus na Terceira Meditação). Além disso, ao estabelecer que a pura extensão matemática é substância de todos os corpos, Descartes, simultaneamente, expulsa da realidade corporal as qualidades ou acidentes reais. É isso o que ele pode deduzir já na Sexta Meditação, logo após provar a existência de uma realidade material de corpos exteriores.

\section{***}

O mais importante, porém, é notar que essa independência, ou melhor, essa autossuficiência ontológica que Descartes confere a essas duas naturezas já radicalmente distintas (a matéria e a alma), ao tratar ambas como substâncias, não está a serviço de uma concepção teológica ou espiritualista, mas, ao contrário, de uma mentalidade racional e científica de desespiritualização da matéria e, simultaneamente, de naturalização do espírito. 
Senão vejamos; apesar das aparências é apenas na filosofia moderna, sobretudo com os primeiros modernos, que a pura matéria pela primeira vez na história da filosofia, de modo hegemônico, vai conquistar o estatuto ontológico privilegiado de substrato único do mundo capaz de explicar sozinha toda a natureza. Em suma: é na modernidade, com Galileu, Kepler, Descartes e Hobbes, entre outros, que a matéria será plenamente elevada à categoria ontológica de substância.

Por um lado, os modernos exorcizaram, desespiritualizaram, desanimaram a natureza, isto é, expulsaram dela as formas, as almas ou psyqués (que para os aristotélicos-tomistas eram responsáveis pela organização da matéria em corpos de diversos gêneros e espécies), e assim, converteram-nos $\boldsymbol{d e}$ organismos autoanimados a puros mecanismos materiais. Por outro lado, os modernos subtraíram da própria natureza material as qualidades ou acidentes reais, isto é, fizeram das qualidades sensíveis meras realidades na mente, representações da nossa subjetividade. Com isso, identificaram a matéria da física com a extensão geométrica e converteram a física numa geometria do movimento. Em suma: fizeram da natureza pura extensão em movimento. ${ }^{6}$

Se Galileu foi propriamente o fundador e também o mais eficaz na criação da nova física-matemática, Descartes foi, sem dúvida, por sua vez, o mais inovador e eficaz na fundamentação metafisica dessa físicamatemática que surgia. Enquanto Galileu limitou-se a uma apropriação mais ou menos fiel do atomismo grego de Demócrito - que concebia o mundo como agrupamentos de átomos em movimento no vazio - Descartes preocupou-se com demonstrar metafisicamente a diferença radical entre matéria e espírito e, sobretudo, a autonomia ontológica de ambas as substâncias. Com isso, Descartes, criou uma nova cosmologia mecanicista que, diferentemente do atomismo, identificava lógica e ontologicamente

\footnotetext{
${ }^{6} \mathrm{~A}$ esse respeito ver, por exemplo, o livro de Alexandre Koyré. Du Monde Clos a L'univers Infini. Gallimard: Paris, 1988.
} 
espaço e matéria e negava ao mesmo tempo a existência dos átomos e do vazio, passando a operar com o conceito de corpúsculo e de movimento rigorosamente mecânico.

A forma exemplar dessa fundamentação metafísica está, como acabamos de mostrar, nas Meditações Metafísicas. É comum afirmar que quando Descartes, na Meditação Segunda, opera uma distinção radical entre corpo e alma, o interesse cartesiano seria, sobretudo, o de mostrar que esta é puramente imaterial e completamente independente daquele. Na verdade, é precisamente o contrário: o que Descartes está interessado é na contrapartida dessa distinção, isto é, ele está interessado em mostrar que o corpo é puramente material e completamente independente de qualquer alma ou forma como pressupunham os aristotélico-tomistas. Tal é a condição necessária para se justificar metafisicamente a elaboração de uma ciência da natureza que tem como objeto apenas a extensão e suas propriedades geométricas e mecânicas, ou seja, tal é a condição necessária para se validar metafisicamente a realização de uma física-matemática. ${ }^{7} \mathrm{Se}$ observarmos com mais cuidado, a distinção entre corpo e alma, que Descartes apresenta na Meditação Segunda, é a negação dos fundamentos metafísicos da física aristotélico-tomista.

Por outro lado, a própria alma, ao se converter em substância, substância puramente pensante, adquire, por assim dizer, uma natureza

\footnotetext{
${ }^{7}$ É por isso que o que vem na sequência da metafísica ou Filosofia Primeira de Descartes não é - como deveria ser se o interesse central de Descartes fosse a prova da imaterialidade da alma - uma psicologia racional, que aprofundaria ou desdobraria em minúcias a natureza e as operações da alma; e nem mesmo uma teologia, como seria o caso - se o interesse central desse filósofo fosse refletir sobre a causa primeira. Nada disso: o que, nas obras de Descartes, segue-se à metafísica é sempre uma física ou filosofia da natureza. Essa é a sequência que Descartes apresenta nos Princípios da Filosofia, e tal é a sequência que Descartes também já tinha apresentado, antes das Meditações, no Discurso do Método, quando, após a fundamentação metafísica que aparece na quarta parte, ele apresenta para uma descrição geral de sua física.
} 
simples e transparente, sem quase nenhum ranço teológico. Enquanto era considerada pela tradição como forma que organizava a matéria em diversos níveis e segundo diversas funções (vegetativa, sensitiva, locomotiva e racional), a alma ( $p$ sykhé, entelékheia) comportava uma natureza intimamente complexa e misteriosa. No que essencialmente consistia a natureza disso que, além de pensar, era capaz de dotar a matéria de movimento e de sensações, de fazê-la alimentar-se e se desenvolver? Com Descartes, porém, mostrou-se que a matéria se organizava sozinha, sem a ajuda da alma, reduzindo-a, assim, ao puro intelecto. Mas não é apenas isso: o próprio intelecto perdeu a sua natureza misteriosa e divina de nous (como era compreendido pela tradição aristotélico-tomista) e foi traduzido como puro pensamento. Em suma, Descartes reduziu a alma à pura função de pensar e fez disso a própria natureza da alma: esta é ser pensamento e vice-versa.

Lembremo-nos de que, no parágrafo quarto da Meditação Segunda, antes da formulação do cogito, Descartes lista também os "espíritos" ao lado de todas as coisas materiais que foram colocadas em dúvida: "Mas eu me persuadi de que nada existia no mundo, que não havia nenhum céu, nenhuma terra, espíritos alguns, nem corpos alguns". Fica claro aqui que a natureza imaterial, tomada no sentido tradicional como a misteriosa psykhé ou entelékheia, era tão ou mais passível de dúvida do que a natureza material. Nenhuma entidade obscura - seja pensada em termos de uma matéria sutil (um vento, um sopro), seja pensada como "algo" imaterial - poderia ter sobrevivido à dúvida, de modo que pudéssemos servir-nos dela para caracterizar o "eu” que pensa como alguma coisa além de puro pensamento.

"Nada sou, pois, falando precisamente, senão uma coisa que pensa, isto é, um espírito, um entendimento ou uma razão, que são termos cuja significação me era anteriormente desconhecida"...8 Nessa passagem Descartes está explicitamente operando uma

${ }^{8}$ Méditations-Seconde, A. T., IX., p. 21; Meditationes - Secunda, A.T., VII, p. 27. 
identificação entre coisa pensante (res cogitans), espírito (mens sive animus), entendimento (intellectus) e razão (ratio). Ele não está dizendo que a alma (coisa pensante) é dotada de espírito, mas que ela é espírito, e que este é pura razão; ou, inversamente, que ele, pura razão, define alma como coisa pensante. ${ }^{9}$ É por isso que Descartes diz que espírito, intelecto e razão eram termos cuja significação lhe era desconhecida até então: esses termos, que ele usa para definir alma, ganham significação na medida em que são definidos como pura natureza pensante. Assim, o termo alma (reduzido ao de espírito) confere ao pensamento o estatuto de coisa (res) e, inversamente, o termo pensamento confere ao espírito (entendido como alma) a sua pura essência. ${ }^{10}$

Ora, ao conceber a alma, assim simplificada, como puro pensamento, frente a uma matéria que produz sozinha os corpos particulares, parece que Descartes está dando os primeiros passos para uma concepção mais moderna e naturalista da mente, que, de entidade mística e divina, converte-se agora em puro ser pensante criado na natureza juntamente com os seres materiais e unido ao corpo humano

\footnotetext{
9 "Mas eu, tendo cuidado que o princípio pelo qual somos alimentados é inteiramente diferente daquele pelo qual pensamos, disse que o nome alma, quando se refere ao mesmo tempo a um e a outro, é equívoco, e que, para tomá-lo precisamente como esse primeiro ato ou essa forma principal do homem, ele deve ser somente entendido como aquele princípio pelo qual pensamos; dessa maneira, chamei-o o mais das vezes pelo nome de espírito, para evitar esse equívoco e essa ambigüidade. Pois não considero o espírito como uma parte da alma, mas como toda a alma pensante" (Quintae Responsiones, A.T, VII, p. 356; Cinquièmes Réponses, JMB, p. 351) (grifo nosso).

${ }^{10}$ Como diz Gilson, entre a alma e o pensamento não há senão uma distinção de razão : "mais ainda, a substância pensante, ou a alma, não é feita, em sua natureza, de outra coisa ao não ser o próprio pensamento [...], e é por isso que o sujeito da Cogitatio se chama Mens, que nos traduzimos hoje por Pensamento, e que Descartes traduzia por espírito. Portanto, quase não correremos o risco de ser infiéis à intenção profunda do filósofo ao considerar seu substancialismo como um simples realismo do pensamento"' (Discours de la Méthode, Texte et Commentaire, op. cit., p. 303 [grifo nosso em negrito]).
} 
como mero pensamento ou inteligência racional. É claro que, na concepção de Descartes, a mente continua sendo vista como um ente imaterial, uma alma, porém, como acabamos de ver, é o próprio conceito de alma que Descartes naturaliza ao identificá-lo com o puro pensamento (ou consciência, como veremos adiante). Está aberto o caminho para, posteriormente na história filosofia, numa nova operação naturalista, entender a mente como pura atividade neurofisiológica (ainda que isso se faça ao preço de implodir a própria distinção entre matéria e espírito herdada da tradição fillosófica por Descartes). ${ }^{11}$

$* * *$

Concentremo-nos, agora, em desembaraçar todo o conteúdo da coisa pensante, a fim de esclarecer melhor sua natureza. Como vimos, Descartes afirma que a coisa pensante é um espírito e que este é um entendimento ou uma razão (mens, sive animus, sive intellectus, sive ratio). ${ }^{12}$ Essa identidade entre coisa pensante ou espírito e entendimento ou razão mostra claramente que a coisa pensante é essencialmente pura inteligência e mais nada.

Quando a inteligência opera sozinha, chama-se mais propriamente entendimento; quando se aplica a imagens, chama-se imaginação; quando se aplica às imagens fornecidas pelos sentidos, chama-se sentir, etc. É o que Descartes afirmava já nas Regras para Direção do Espírito:

...Deve-se conceber que essa força pela qual conhecemos propriamente as coisas é puramente espiritual... Que, ademais, ela é única [...] É uma única e mesma força que, aplicando-se com a imaginação ao sentido comum, é chamada de ver, tocar, etc.; que,

\footnotetext{
${ }^{11}$ Ver, por exemplo, a concepção materialista da alma que Hobbes desenvolve no Leviatã , publicado em 1651 (lembrando que o essencial da teoria cartesiana da alma já havia sido publicado desde 1637, na quarta parte do Discurso do Método)

${ }^{12}$ Méditations -Seconde, A. T., IX., p. 21; Meditationes-Secunda, A.T., VII, p. 27.
} 
aplicando-se à imaginação sozinha na medida em que essa é guarnecida de figuras diversas, é chamada de lembrar-se; que, aplicando-se à imaginação para dela formar novas imagens é chamada de imaginar ou conceber; que, enfim, agindo sozinha, é chamada de compreender. ${ }^{13}$

O que é essencial à inteligência é, naturalmente, o inteligir, a intelecção. O intelecto, ou o entendimento, é, portanto, a faculdade essencial; todas as demais faculdades, na medida em que dependem da união do espírito com o corpo, são-lhe acidentais.

A intelecção consiste na apreensão intelectual de um determinado conteúdo. Como se trata de uma apreensão intelectual, isto é, feita por uma inteligência, significa que tal apreensão produz a inteligibilidade do conteúdo apreendido que produz, portanto, a ideia do conteúdo apreendido. Quando se trata de uma apreensão pura do intelecto, feita, portanto, a partir de conteúdos puramente intelectuais, isso se chama de intuição intelectual, intuitus mentis; quando se trata de uma apreensão que o intelecto faz de objetos dados pelos sentidos, chamamos isso de sensação ou percepção sensível.

Como, porém, a inteligência não é atributo da matéria e, portanto, não tem o corpo como seu sujeito, mas é atributo de si mesma e, portanto, é sujeito de si mesma, a inteligência é, antes de qualquer coisa, inteligibilidade de si mesma. Antes de produzir a inteligibilidade de qualquer outra coisa, ela é já inteligível a si mesma. A inteligência, portanto, é originariamente reflexiva, ou melhor, autorreflexiva: ela é seu primeiro e inalienável objeto de intelecção. ${ }^{14}$ Daí porque o

\footnotetext{
${ }^{13}$ Regulae ad Directionem Ingenii - Regula XII, AT, X, p. 415-416 (grifo nosso).

${ }^{14}$ É por isso que Descartes responde a Gassendi que a coisa pensante não tem necessidade de outro objeto além de si mesma para exercer sua ação (Sur Les Cinquièmes Objections, AT., IX, p. 206): se o pensamento, na medida em que é atributo de si mesmo, é originariamente consciência-de-si, então ele é originariamente objeto de si mesmo. E é também porque o pensamento éoriginariamente consciênciade-si que Descartes pode afirmar, em resposta a Arnauld, que não há nada no
} 
cogito é a primeira verdade que inaugura o edifício do conhecimento.

Mas, se a coisa pensante é originariamente consciência-de-si, ${ }^{15} \mathrm{O}$ cogito não é a produção da consciência-de-si, mas tão somente a sua atualização. Além disso, se a consciência-de-si é o dado original, então a consciência de qualquer outra coisa é um modo da consciência-de-si. Esta não é uma forma posterior de consciência, mas, pelo contrário, qualquer forma de consciência é já um modo da consciência-de-si. Eu só posso ter consciência de um objeto porque eu próprio sou uma consciência e, enquanto tal sou, portanto, consciência de mim mesmo. Há aqui, portanto, uma posição diametralmente oposta àquela que, posteriormente,

espírito de que não tenhamos consciência (Quatrièmes Réponses, A.T., IX, p.190; Quartae Responsiones, AT, VII, p. 246.): ser espírito é ser consciência. Logo, estar no espírito é precisamente estar na consciência, tudo o que está ali é conteúdo de consciência. Mas isso não significa que tenhamos consciência (sejamos conscientes) de todos os nossos conteúdos de consciência (pensamentos). Essa diferença é explicada por Descartes numa troca de correspondência com Arnauld. Segundo Arnauld, a concepção cartesiana de que sempre devemos ter consciência de nossos pensamentos parece ser contrária à experiência dos sonhos, visto que quase nunca lembramos daquilo com que sonhamos. Descartes the responde que "uma coisa é ter conhecimento de nossos pensamentos no momento mesmo em que pensamos, outra coisa é se lembrar deles depois. Assim, não pensamos nada nos sonhos que, no instante mesmo em que pensamos, não tenhamos conhecimento de nosso pensamento, ainda que na maior parte das vezes o esqueçamos tão logo" (Correspondance, A.T., V, carta DXXV, 29 juillet 1648, p. 221; Correspondance avec Arnauld et Morus, op. cit., p. 89).

Portanto, o que Descartes afirma não é que sempre nos lembramos de todos os nossos pensamentos, que nunca os esquecemos e que, portanto, sempre temos consciência deles. Ele apenas afirma que no momento em que pensamos alguma coisa, sempre temos consciência desse pensamento, ou seja, que não há como pensar sem ter, ao mesmo tempo, consciência daquilo que pensamos.

15 A alma, então, é originariamente ideia de si mesma. A concepção cartesiana da alma é assim oposta aquela de Espinosa, para quem a alma é ideia do corpo (Ética II, proposição XIII, in col. "Os Pensadores”, São Paulo, Abril Cultural, 1983, p. 143144), e a consciência de si, portanto, é a consciência de si enquanto consciência do corpo e, portanto, ela só se conhece a si mesma na medida em que percebe as idéias das afecções do corpo (Ética II, proposição XXIII, Ibid., p. 153). 
Kant ${ }^{16}$ e, mais contemporaneamente, Husser ${ }^{17}$ assumem, quando afirmam que a consciência-de-si é mediada pela consciência do objeto. Para Descartes é justamente o contrário: a consciência do objeto é que é mediada pela consciência-de-si.

Enfim, de tudo isso resulta que para Descartes (visto que a coisa pensante é essencialmente consciência-de-si) o pensamento é igual à consciência. Daí porque, na exposição geométrica, o filósofo define pensamento como "tudo quanto está de tal modo em nós que somos imediatamente seus conhecedores". Em latim ele é mais explícito ainda: "tudo quanto está de tal modo em nós de que estamos imediatamente conscientes". ${ }^{18}$ É por isso que a própria ideia, enquanto forma de pensamento ou ato de intelecção, é definida também no contexto da consciência: "pelo nome idéia entendo esta forma de cada um de nossos pensamentos por cuja percepção imediata temos conhecimento (em latim: somos conscientes) desses mesmos pensamentos". ${ }^{19}$

Mas há ainda outra coisa a se deduzir da definição cartesiana do pensamento como coisa ou substância. Se a inteligência não tem o corpo como sujeito, mas é sujeito de si mesma, então significa que ela não é um simples instrumento do corpo, operada por ele, mas opera autonomamente por si mesma, isto é, tem em si mesma o seu princípio de ação. A inteligência em Descartes é, portanto, essencialmente livre. É por isso que ela não tem simplesmente uma faculdade passiva de apreender conteúdos (intelecto ou entendimento), mas também uma faculdade ativa de afirmá-los, negá-los ou pô-los em dúvida e por isso também que ela pode selecionar o objeto de sua intelecção, isto é, escolher qual entre os objetos dados - seja pelos sentidos, seja na memória, seja objetos inatos - ela quer inteligir; é por isso mesmo que ela própria

\footnotetext{
${ }^{16}$ Crítica da Razão Pura, B 158-157.

${ }^{17}$ Idées directrices pour une phénoménologie, Paris, Gallimard, 1950, p. 91.

${ }^{18}$ Secundae Responsiones, AT VII, p. 160; Secondes Reponses, AT IX, p. 124. ${ }^{19}$ Ibid.
} 
pode inventar objetos para sua intelecção, desenhando imagens na fantasia, modificando e combinando arbitrariamente as figuras dadas. A inteligência, então, não é apenas dotada da capacidade de inteligir, mas da capacidade de agir sobre o que intelige ou pode inteligir. Em suma: a coisa pensante é dotada de entendimento e vontade.

Nos Princípios da Filosofia, Descartes afirma:

todas as maneiras de pensar que experimentamos em nós podem reduzir-se a duas gerais. Consiste uma em apreender pelo entendimento e a outra em determinar-se pela vontade. Assim, sentir, imaginar e mesmo conceber coisas puramente inteligíveis são formas diferentes de apreender; mas desejar, ter aversão, confirmar negar, duvidar, são formas diferentes de querer. ${ }^{20}$

Numa carta a Regius, Descartes assim se expressa:

então onde dizes, a vontade e o entendimento verdadeiramente diferem na medida em que são diversos modos de agir acerca de diversas coisas, eu acharia preferível: diferem tanto quanto ação e paixão da mesma substância. O entendimento, pois, é a propriamente paixão da mente, a vontade a sua ação. Mas porque jamais queremos nada que não entendamos ao mesmo tempo, e dificilmente entendemos qualquer coisa ao mesmo tempo em que não queiramos algo, por essa razão não distinguimos facilmente a paixão da ação. ${ }^{21}$

Eis, pois, que a coisa pensante, sendo originariamente inteligência de si mesma, é uma inteligência essencialmente livre. Entendimento e vontade são, dessa forma, os dois atributos da coisa pensante, de modo que, como diz Descartes, “jamais queremos nada

\footnotetext{
${ }^{20}$ Príncipes, Première Partie, § 32, AT, IX, p. 39.

${ }^{21}$ Descartes a Regius, maio de 1641, AT III, p. 372 (grifo nosso).
} 
que não entendamos ao mesmo tempo, e dificilmente entendemos qualquer coisa ao mesmo tempo em que não queiramos algo". Todavia, só o entendimento é atributo essencial: a vontade é atributo da inteligência, mas a inteligência é atributo de si mesma. A inteligência, portanto, é uma faculdade (entendimento) e a própria coisa de que ela é faculdade; ${ }^{22}$ a vontade, por sua vez, é tão-somente uma faculdade da inteligência. É claro que na medida em que a inteligência é originariamente inteligência de si mesma, a vontade resulta como uma faculdade necessária, mas ela não define o ser da inteligência: é possível pensar a inteligência sem vontade, enquanto que esta não pode ser pensada sem aquela.

É por isso que, com respeito ao entendimento, Descartes afirma, de modo absoluto, que "jamais queremos algo sem, ao mesmo tempo, entender; enquanto que, com respeito a vontade, eles diz somente que, dificilmente entendemos qualquer coisa sem, ao mesmo tempo, querer algo". Quer dizer, eu não posso querer sem entender, mas é possível entender sem querer.

Dessa forma, podemos dizer que não há nada na inteligência que não seja objeto de inteligência, ou melhor, não há nada na coisa pensante que não seja objeto de seu entendimento. Isso se torna mais claro se nos lembrarmos de que a inteligência é originariamente reflexiva e que, portanto, todo e qualquer pensamento é uma modificação da consciência. Assim, podemos dizer que não há nada na coisa pensante que não seja objeto de consciência.

Inteligir, como já dissemos, significa apreender intelectualmente

${ }^{22}$ É por isso que Descartes responde a Hobbes "o pensamento toma-se às vezes pela ação, algumas vezes pela faculdade, e outras ainda pela coisa na qual reside a faculdade. E não digo que a intelecção [ação de entender] e a coisa que entende sejam a mesma coisa, e nem mesmo digo que a coisa que entende e o entendimento sejam o mesmo se o entendimento for tomado por uma faculdade, mas somente quando ele [o entendimento] é tomado pela coisa mesma que entende." (Objectiones Tertiae, AT VII, p. 174; Troisièmes Objections et Réponses, AT IX, p. 135). 
um conteúdo, isto é, formar a ideia de uma determinada coisa. A ideia, portanto, é um modo do entendimento, ou uma modificação do intelecto. Toda ideia, porém, à medida em que é apreensão de um determinado conteúdo, apresenta um determinado objeto para o entendimento. $\mathrm{O}$ objeto, assim presente ao entendimento, é o que Descartes chama de realidade objetiva ou ser por representação. Representação, portanto, é a apresentação da coisa ao entendimento. Se essa apresentação ao entendimento é clara e distinta, a coisa se mostra ao entendimento tal qual ela é em si mesma; mais que isso: ela mostra se corresponde a alguma coisa exterior ao entendimento (tal como a ideia de Deus) ou se ela não passa de uma coisa no entendimento (tal como os conteúdos matemáticos); se for obscura e confusa, então a coisa apresentada ao entendimento não é capaz de mostrar se corresponde a uma coisa exterior e, em caso positivo, se a representa fielmente (tal é o caso das idéias sensíveis).

Toda a questão cartesiana, portanto, consiste em saber se as coisas apresentadas ao entendimento correspondem a coisas exteriores e, portanto, se há uma realidade exterior à realidade pensante.

Como podemos notar, pensamento e representação não são sinônimos e nem mesmo equivalentes em Descartes. Toda a representação é pensamento, mas o pensamento não se resume à representação. Mais do que simples representação, o pensamento é ele próprio uma coisa que representa. O pensamento é uma coisa, uma realidade; a representação é uma realidade no e para o pensamento. A representação, portanto, não esgota toda a realidade do pensamento. Mais que isso: ela não esgota a realidade do entendimento e nem mesmo a realidade da idéia. Uma ideia não é meramente uma representação: é antes de tudo uma intelecção, um ato de apreensão do intelecto; a representação é o que resulta desta apreensão. Além disso, a ideia não esgota toda a realidade do entendimento: há também os princípios lógicos, que são apenas noções comuns, mas não propriamente idéias e, portanto, não envolvem 
representação. ${ }^{23}$ Por fim, além da intelecção, a inteligência, como vimos, também é dotada da faculdade Vontade e, como tal, afirma, nega, duvida, quer, não quer. Tais ações, é claro, não consistem em representações.

É claro que, embora desejar ou julgar não sejam propriamente conceber, para que eu possa desejar ou julgar a respeito de alguma coisa é preciso que eu conceba uma tal coisa. Como afirma Descartes, pode haver ideia sem juízo ou volição, mas não o contrário. ${ }^{24}$ Um juízo ou uma volição se faz sempre a partir de e sobre uma ideia. Além disso, o conteúdo de uma ideia pode ser qualquer coisa, inclusive nossas próprias afecções, volições, juízos, etc. É isso também que Descartes responde a Hobbes quando afirma que ideia é tudo aquilo que é concebido imediatamente pelo espírito: "de sorte que, quando quero ou temo, porque ao mesmo tempo concebo o que quero ou temo, esse querer e esse temor são colocados por mim no rol das idéias". ${ }^{25}$ Em suma: embora nem todo pensamento seja ideia, todo pensamento pode ser objeto de ideia. E de fato é mesmo: se ideia é uma percepção da alma, se esta é uma coisa puramente pensante (res cogitans), e se a coisa pensante é essencialmente consciência-de-si, então, como afirma o próprio Descartes, não há nada no espírito de que não tenhamos consciência, ${ }^{26}$ isto é, de que não tenhamos uma percepção ou ideia. E, como toda a ideia envolve uma representação,

23 “Quando pensamos que nunca se poderá fazer alguma coisa do nada, não cremos que tal proposição seja coisa que exista ou propriedade de alguma coisa, mas tomamo-la por uma certa verdade eterna que tem seu lugar no pensamento e a que se chama noção comum ou máxima" (Principes - Première Partie, A.T., IX, § 49, p. 46).

24 “....confesso que não queremos nada do qual não concebamos alguma coisa, de qualquer maneira que seja". (Quintae Responsiones, A.T., VII, p. 377; Cinquièmes Réponses, JMB, p. 366)

${ }^{25}$ Troisièmes Objections, A.T., IX, p. 141; Objectiones Tertiae, A.T., VI, p. 181 (tradução nossa).

${ }^{26}$ Quatrièmes Réponses, A.T., IX, p.190; Quartae Responsiones, A.T., VII, p. 246 (tradução nossa). 
então podemos dizer que não há nada no espírito de que não tenhamos uma representação.

Todavia, ainda assim, o próprio espírito, isto é, a coisa pensante ou a inteligência não é ela própria uma representação, e nem são representações as suas faculdades. A coisa pensante é uma substância tão real quanto à coisa corpórea, embora ambas possam ser objeto de representação da coisa pensante. A representação é uma realidade no pensamento, mas ela não o constitui e, portanto, não o define. É por isso que, como já vimos na Exposição Geométrica, Descartes oferece separadamente a definição de pensamento, ideia e representação.

$* * *$

Por fim, após ter esclarecido a estrutura e o funcionamento da coisa pensante ou espírito, convém atentar agora para o alerta que Descartes já nos faz no parágrafo 8 da própria Meditação Segunda. Ali, depois de ter se afirmado como pura coisa pensante, Descartes alerta:

Mas também pode ocorrer que essas mesmas coisas que suponho não existirem [as coisas materiais], já que me são efetivamente desconhecidas, não sejam efetivamente diferentes desse $e u$ [na medida em que teria um corpo] que agora conheço [como sendo apenas espírito]? Nada sei a respeito; não o discuto atualmente, não posso dar meu juízo senão a coisa que me são conhecidas: reconheci o que eu era, e procuro o que sou, eu, que reconheci ser. ${ }^{27}$

Essa passagem, sobretudo a partir de Gueroult, tem sido, ao meu ver, muito erroneamente interpretada. Descartes não estaria aqui duvidando, como pensa Gueroult, que o conhecimento que eu tenho da natureza de meu espírito possa não corresponder à natureza real de meu

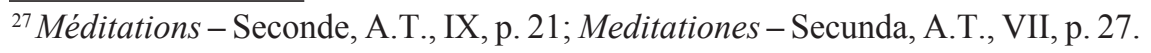


espírito. ${ }^{28}$ Esse tipo de situação só poderia ocorrer no contexto da dúvida metafísica, tal como efetivamente ocorreu com as verdades matemáticas. Todavia, se o cogito se constituiu como primeira verdade, foi na medida mesma em que ele é o único a escapar da dúvida metafísica. Se, portanto, conheço meu espírito como coisa puramente pensante, distinta da matéria, então de fato meu espírito é uma coisa puramente pensante, distinta da matéria.

Não vou aqui discutir em minúcia as razões pelas quais considero inaceitável a interpretação gueroultiana. ${ }^{29}$ Apenas gostaria de aproveitar a ocasião para alertar que essa interpretação gueroultiana serve, além disso, para alimentar outro grande erro de leitura, qual seja, o de que a concepção cartesiana de subjetividade humana se reduz essencialmente à concepção cartesiana de puro espírito.

Segundo meu ponto de vista, dados os interesses e a lógica interna da empresa cartesiana, a passagem em questão da Meditação Segunda só pode ser concebida como significando o seguinte: "embora a essa altura da Meditação Segunda eu reconheça que, enquanto res cogitans, eu seja apenas uma natureza puramente espiritual, isso não implica que eu não possa ser também uma res extensa, isto é, que eu não possa ser dotado de um corpo, ao qual meu espírito estaria intimamente ligado, compondo uma única coisa, tal como me parece ser percebido pelos meus sentidos."

Quer dizer, Descartes não está colocando em dúvida a correspondência entre o conhecimento que tenho de minha natureza espiritual e a realidade dessa mesma natureza. O que ele está questionando é se o conhecimento que tenho, no estágio da Meditação Segunda, de que sou unicamente um puro espírito, seria incompatível com conhecimento que, ainda não posso ter, de que eu, além de puro

\footnotetext{
${ }^{28}$ Descartes Selon L'Ordre des Raisons. Paris: Aubier, 1953, p. 89.

${ }^{29}$ Já tratei disso longamente no meu livro A Teoria Cartesiana da Verdade. Humanitas/Unijui: São Paulo, 2006, capítulo IV, p. 25-49), onde submeti a posição de Gueroult a uma crítica detalhada.
} 
espírito, posso também ser dotado de um corpo.

Se for assim, então Descartes está expressamente alertando para o fato de que o puro espírito não constitui sozinho a minha subjetividade, mas é apenas uma abstração de ordem metafísica da minha subjetividade concreta. Quer dizer, o sujeito metafísico, o espírito, seria apenas uma abstração do sujeito concreto e não a sua definição.

Dessa forma, a prova da distinção real entre espírito e corpo, presente na Sexta Meditação, não pretende mostrar que, enquanto espírito, sou puramente imaterial (pois isso já está estabelecido desde a Segunda Meditação). O que ele pretende é mostrar que, visto a extensão ser uma essência real (tal como ficou provado na Quinta Meditação), então ela é realmente distinta do espírito e, por isso, aquelas imagens de coisas extensas presentes à mente, incluído aí a representação do meu próprio corpo, não podem ser produzidas pelo próprio espírito. Com isso fica aberta a possibilidade de que as representações de coisas extensas tenham sido produzidas pelos próprios corpos de que elas seriam representações e, portanto, que as coisas corpóreas existam e, sobretudo, que eu próprio, além de espírito, tenha um corpo unido a ele compondo uma única coisa. Como sabemos, tal possibilidade será efetivamente provada verdadeira na sequência da argumentação cartesiana.

Tudo isso fica mais claro se compreendermos bem o significado de união substancial corpo e alma sustentada pela filosofia cartesiana. Descartes insiste na Sexta Meditação que a alma não está alojada no corpo como um piloto em seu navio, mas que está intimamente ligada a ele, de modo a compor uma única coisa.

A natureza me ensina, também, por esses sentimentos de dor, fome, sede, etc., que não somente não somente estou alojando em meu corpo, como um piloto em seu navio, mas que, além disso, lhe estou conjugado tão estreitamente e de tal modo confundido e misturado que componho com ele um único todo. Pois se assim não fosse, quando meu corpo é ferido não sentiria por conta disso nenhuma dor, eu que não sou senão uma coisa pensante, e apenas perceberia 
esse ferimento pelo entendimento, como o piloto percebe pela vista se algo se rompe em seu navio ${ }^{30}$ (Meditação Sexta, parágrafo 24).

Notemos que os acontecimentos e os estados corporais não são observados pela alma como eventos exteriores a ela, que ocorrem distintamente no corpo ao qual ela se percebe unida; pelo contrário, tais eventos são assimilados à alma como acontecimentos e estados dela, isto é, como acontecimentos e estados mentais. Não há, portanto, primeiramente uma experiência corporal que então, num segundo momento, é percebida pela alma como ocorrendo no corpo ao qual está unida, mas há uma experiência única e indistinta que é sempre vivenciada como sendo da alma. ${ }^{31}$

É a própria alma que sente fome ou sede. Sem dúvida, a carência de alimento ou de água são estados corpóreos, mas os sentimentos dessas carências são estados mentais, e são a esses sentimentos que propriamente chamamos de fome ou sede. Do mesmo modo, é a alma que vê objetos exteriores, que escuta sons. A visão ou audição são processos neurofisiológicos e, portanto, corporais, mas a consciência da visão ou da audição são processos mentais da alma e é a isso que mais propriamente chamamos de visão ou som. ${ }^{32}$

É por isso que os sentimentos, ou as paixões, são sentimentos ou

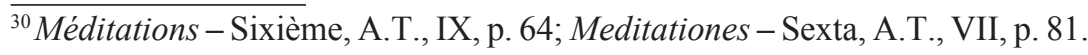

31 “É preciso, além disso, tomar cuidado para não supor que, para sentir, a alma tenha necessidade de contemplar algumas imagens que sejam enviadas pelos objetos até o cérebro". (La Dioptrique, A.T., VI, p. 112) "Ora, ainda que essa pintura, ao passar assim até o interior de nossa cabeça, retenha sempre a semelhança dos objetos de onde ela procede, não é preciso, todavia, persuadir-se, assim como eu já recém vos fiz suficientemente entender, que seja por meio desta semelhança que ela faça que nos os sintamos, como se houvesse novamente outros olhos em nosso cérebro, com os quais nós a pudéssemos perceber" (Ibid., p. 130. Tradução e grifo nossos).

32 "Primeiramente, porque é a alma que vê, e não o olho, e porque ela apenas vê imediatamente por meio do cérebro..." (La Dioptrique, A.T., VI, p. 141. Tradução nossa).
} 
paixões da alma. O corpo propriamente não sente, mas realiza processos que sensibilizam a alma. Ele é um puro mecanismo, uma máquina. As afecções corpóreas, externas ou internas, não são propriamente sensações, mas processos mecânicos de comunicação de movimento entre as partes..$^{33}$

Se isso, por um lado, mantém a alma como sujeito de toda a experiência humana, por outro lado, amplia a vida da alma para além do território puramente espiritual e faz com que ela se confunda com a vida do corpo e a assimile como vivência sua.

A res cogitans é comum a todo ser humano: é uma substância pensante, autoconsciente, dotada também da ideia de Deus, bem como das essências e das relações essenciais do mundo material exterior. A diferença entre uma res cogitans particular e outra é apenas numérica. $\mathrm{O}$ Eu que, na formulação do cogito, se afirma existente na medida em que pensa, e enquanto tal se conhece como natureza puramente espiritual, não é Descartes ou qualquer outra pessoa que realiza as meditações metafísicas. Trata-se do Eu puramente racional, comum a todo ser humano, que se revela por detrás da desconstrução do sujeito particular concreto. Tratase, em outras palavras, da própria razão humana que se expressa em cada pessoa, independentemente dessa expressão pessoal.

Sendo assim, o, por assim dizer, princípio de individuação, está no corpo específico com que cada res cogitans em particular está unida. Cada corpo é, por sua vez, diferente de outro, não apenas pelo seu volume, sua massa, sua figura, e toda uma série de características físicas particulares, mas, sobretudo, pela sua posição espaço-temporal única. Cada corpo, desde seu nascimento, ocupa uma posição espaço-temporal exclusiva e, a partir dela, estabelece relações únicas com os corpos que os rodeiam e com o meio ambiente em geral, constituindo sua história particular de vida.

\footnotetext{
33 “Sabemos já suficientemente que é a alma que sente, e não o corpo [...] E sabemos que não é propriamente na medida em que ela está nos membros que servem de órgãos aos sentidos exteriores, que ela sente, mas na medida em que ela está no cérebro, onde exerce esta faculdade que chamam de sentido comum". (Ibid., A.T., VI, p. 109).
} 
As paixões da alma unidas a um corpo $\mathrm{X}$, nascido em tal lugar e em tal época, em tal família, serão intrinsecamente diversas das paixões de uma alma unida a um corpo $\mathrm{Y}$, e assim por diante. Sendo assim, sobre o núcleo lógico, puramente racional, que fundamenta a vida do espírito (núcleo comum a cada res cogitans), às paixões - que cada alma obtém do corpo específico com o qual está unida desde o seu nascimento - vão sobrepondo-se camadas psicológicas, que, progressivamente, formam as subjetividades particulares não só diferentes em número, como no ponto de partida, mas verdadeiros indivíduos, efetivas personalidades individuais.

Assim, podemos dizer que as paixões da alma não são meros veículos de informação dos acontecimentos e estados corporais, não tem mero papel funcional, mas são elementos constitutivos da subjetividade humana, ou seja, são aqueles que vão construir sobre a mera subjetividade lógica da razão, a subjetividade psicológica do animal-racional. Enfim, o sujeito humano (o animal racional) segundo Descartes, não é uma mera res cogitans que, na sua pureza intocável, se serviria do corpo e das paixões para obter meras informações sobre o mundo material exterior. Não! O sujeito humano é aquela personalidade, aquele indivíduo, que será constituído historicamente pelas sucessivas sedimentações de camadas psicológicas sobre o núcleo lógico comum da res cogitans.

***

É por isso que se na Meditação Segunda temos a clássica teoria da alma racional (ou espírito), tradicionalmente chamada de psicologia racional, que é por excelência um assunto de metafísica, uma disciplina filosófica. Com o Tratado das Paixões, Descartes como que preconiza a moderna Psicologia, entendida agora como ciência autônoma (e não mais uma disciplina filosófica), que trata da alma na sua condição terrena de razão corporificada de um sujeito não mais constituído puramente de pensamentos, mas, igualmente, de paixões. 
Descartes tem tanta consciência de sua originalidade que se considera já no artigo $1^{\circ}$ do Tratado como aquele que, pela primeira vez, irá fazer rigorosamente uma ciência das Paixões. ${ }^{34}$ Norteado por sua concepção racionalista de fornecer uma ciência verdadeira de todas as coisas a que a razão pode ter acesso, e acreditando ter encontrado, para a realização de tal empresa, o verdadeiro método, de inspiração geométrica - o método da ordem e da medida - Descartes, se propôs, primeiramente, a estabelecer os fundamentos absolutos da ciência, elaborando sua nova metafísica; na sequência, ele deduziu toda uma cosmologia, isto é, uma explicação geral da natureza, que é a sua física-geométrica, enfim, com o Tratado da Paixões, Descartes julga ser possível deduzir, segundo os princípios gerais de sua física, uma ciência das paixões humanas.

Tal como declara numa das cartas que servem de prefácio a sua obra, é como um fisico que ele pretende abordar o tema das paixões. ${ }^{35}$ Essa ambição cartesiana, que resultou no Tratado das Paixões, talvez seja a primeira tentativa na história da filosofia e da ciência em elaborar uma explicação psico-fisiológica das paixões.

Nesse Tratado, aliás, Descartes não apenas não vai considerar o espírito puro, mas encarnado, como tão pouco, para produzir um tal conhecimento irá utilizar-se do entendimento puro: ele vai fazer uso do entendimento à medida que este não opera isoladamente, debruçandose sobre os conteúdos inatos a si mesmo (o que é propriamente o uso puro do entendimento), mas do entendimento na medida em que este considera as paixões causadas nele pelo corpo. É sempre pelo

\footnotetext{
34 "Não há nenhuma coisa em que melhor apareça quão defeituosa são as ciências dos antigos do que naquilo que escreveram sobre as paixões ... Eis por que serei obrigado a escrever aqui do mesmo modo como se tratasse de uma matéria que ninguém antes de mim houvesse tocado..." Les Passions de l'Âme - Première Partie, Artigo I, AT. XI, p. 327-328.

35 "meu desejo não foi o de explicar as paixões como um Orador, nem mesmo como filósofo moral, mas somente como um físico!". Les Passions de l'Âme, AT XI, p. 326.
} 
entendimento que se pode conceber o sujeito cartesiano, seja como res cogitans (o que é feito pelo entendimento puro), seja como animal racional (o que é feito pelo entendimento que, agora, considera as paixões da alma obtidas pela sua relação com o corpo).

É isso mesmo que Descartes pretende com o Tratado das Paixões da Alma, a saber, produzir um discurso cognitivo sobre as paixões humanas.

Tal obra, como sabemos, consiste num pequeno estudo dividido em três partes. Na primeira parte, é exposta mais propriamente a teoria psico-fisiológica com a qual Descartes poderá definir, na sua generalidade, o que são, estritamente, as paixões da alma, no sentido propriamente psicológico como entendemos hoje. Tais paixões serão, na segunda e terceira parte do tratado, os objetos de um estudo genético (ou funcional) e de uma reflexão moral: na segunda parte, ele trata do número e da ordem das paixões e passa à explicação daquelas que ele considera serem as seis primitivas (admiração, amor e ódio, desejo, alegria e tristeza; enfim, na terceira parte, Descartes mostra como dessas seis paixões originam-se todas as outras.

Efetivamente, a primeira parte do Tratado é a mais importante, porque nela Descartes apresenta sua teoria geral sobre o assunto, fornecendo mesmo a regra moral geral. Esta é composta de 50 artigos e podemos dividi-la em 5 grandes partes. Do artigo 1 ao 16, descreve quais são as funções do corpo. Ele inicia, no artigo 1, com uma condenação do tratamento pouco racional que os filósofos deram sobre a questão até sua época (p. 227). Como a natureza humana é um composto substancial de corpo e alma, antes de estabelecer o que são propriamente as paixões da alma, é preciso distinguir entre as suas funções aquela pertencente ao corpo. Notemos aqui como Descartes vai se utilizar do seu famoso preceito de clareza e distinção: usar toda a luz do entendimento para distinguir o mais claramente possível entre as funções da alma e do corpo. Até o artigo 16, portanto, Descartes descreve quais são a funções corporais, atribuindo como capacidade do corpo humano tudo aquilo que 
pode ser atribuído aos outros animais. Nessa trajetória, Descartes faz breves descrições físiológicas (já contida em outros de seus trabalhos, tais como a Dióptrica e o Tratado do Mundo) das partes do corpo e de algumas de suas funções, descrevendo a circulação do sangue, como princípio fundamental de animação do corpo, descrevendo os movimentos musculares e os reflexos condicionados, bem como descrevendo o mecanismo neurofisiológico das sensações.

$\mathrm{Na}$ segunda parte, que engloba os artigos 17 a 29, Descartes, pela caracterização das funções da alma, vai chegar à definição do que é paixão no estrito senso. Ele inicia por estabelecer que todas as funções da alma são relativas ao pensamento; que pensamento pode ser distinguido em dois gêneros: como ação e percepção - que as ações são relativas à vontade da alma - e que as percepções que a alma tem podem ser causadas ou por sua própria vontade ou pelo corpo ao qual ela está unida. Entre as percepções produzidas pelo corpo - tanto as internas (de fome, sede etc.) quanto às externas (que são as impressões dos objetos exteriores em nós) - são comuns ao corpo e à alma. Destas, porém, Descartes distingue os efeitos emocionais que tais sensações produzem na alma, tais como amor, tristeza, alegria, etc. Essas últimas são precisamente as chamadas paixões da alma.

$\mathrm{Na}$ terceira parte, que vai do artigo 30 ao 47, Descartes, em posse da distinção entre a funções corporais e espirituais, bem como da correta concepção de paixões, volta então a tratar da união corpo e alma, com o objetivo de descrever a forma dessa união e como opera o mecanismo das paixões. Primeiramente, Descartes esclarece que a alma, como uma unidade espiritual e, portanto, indivisível está unida inteiramente ao corpo, este entendido como uma unidade mecânica; então ele mostra que, apesar dessa união inteira com o corpo, o lugar por onde ela propriamente opera, a sede de suas funções, é a glândula pineal situada no meio do cérebro. Na sequência, Descartes passa a tratar propriamente do mecanismo das paixões, demonstrando como alma $\mathrm{e}$ corpo agem um sobre o outro. Ele retoma, brevemente, a explicação do 
mecanismo fisiológico, mas agora adicionando a esfera psíquica: as imagens recebidas por cada um dos olhos é projetada invertida no fundo do cérebro e, a partir daí vai ser transmitida à glândula pineal onde resultará unificada e na posição correta; ora, na medida em que um tal imagem consiste, por exemplo, "numa figura muito estranha ou apavorante, que tenha relação com coisas nocivas que foram nocivas ao corpo numa vez anterior, isso excita na alma a paixão do medo, e, em seguida, a de ousadia ou de terror, de acordo com os diversos temperamentos ou forças da alma, e conforme nos tenhamos nos comportado na ocasião similar anterior". ${ }^{36}$ Ainda nessa terceira parte, Descartes pode, então, definir a função das paixões como sendo a de incitar ou dispor a alma a querer aquelas coisas para as quais elas preparam os corpos. Daí Descartes conclui que, apesar disso, a alma é livre e pode operar com as paixões, entretanto, ele observa que o poder da alma com respeito às suas paixões é limitado e não se faz diretamente; que quando há um conflito entre as intenções da alma e os apetites corporais, ela não pode simplesmente subtrair as paixões ou produzir novas paixões opostas, mas é obrigada a usar de engenho para não ser vencida.

Finalmente na última parte, que inclui os artigos 48, 49 e 50, Descartes afirma que toda a força da alma está em saber operar com as paixões, baseada no conhecimento do que é certo ou errado. Então, ele pode estabelecer como princípio de virtude, como regra moral, combater as paixões com "juízos firmes e determinados sobre o conhecimento do bem e do mal, consoante aos quais ele resolveu conduzir suas ações". Descartes, no entanto, ressalta que, na impossibilidade de sabermos quais são realmente os verdadeiros juízos para agir, devemos nos guiar por aqueles que a razão nos mostra ser os mais prováveis. A irresolução é a pior coisa. A alma fraca é aquela que se deixa levar pelas paixões e não dispõe dos seus próprios recursos para combatê-las. Finalmente, Descartes declara que qualquer alma bem

${ }^{36}$ Les Passions de l'Âme, AT XI, Artigo 36, p. 356. 
conduzida pode adquirir poder absoluto sobre suas paixões.

Numa carta à rainha Cristina, da Suécia, Descartes assim se expressa:

não vejo como seja possível dispor-se melhor dela [da vontade] do que tendo sempre uma firme e constante resolução de fazer exatamente todas as coisas que se julga ser as melhores, e de empregar todas as forças de seu espírito em bem conhecê-las. É nisto unicamente que consistem todas as virtudes; é isto unicamente que, propriamente falando, merece o louvor e a glória; é disso que resulta sempre o maior e mais sólido contentamento da vida. Assim, estimo que é nisto que consiste o soberano bem. [...] Assim, a virtude não consiste senão na resolução e no vigor com o qual se leva a fazer as coisas que se crê serem boas, dado que este vigor não resulte de teimosia, mas de se saber tê-las examinado tanto quanto é moralmente possível. ${ }^{37}$

Em suma, tanto no conhecimento da verdade quanto na prática do bem, todo o mérito humano consiste em educar, em disciplinar rigorosamente a nossa vontade para que possamos agir segundo o nosso assentimento, assentir segundo nosso entendimento e entender sempre o mais clara e distintamente possível o que é bom e verdadeiro.

$$
\text { *** }
$$

Notemos como toda essa descrição presente no Tratado das Paixões da Alma impede a tentação (facilmente inspirada por uma leitura

37 Descartes a Christine de Suède, 20 de novembro de 1647, AT. V, p. 83-84. Descartes repete aqui aquilo que ele já havia afirmado, quase nos mesmos termos, à princesa Elisabeth: "ter uma vontade firme e constante de executar tudo o que julgamos ser o melhor, e de empregar toda a força que o nosso entendimento tem em bem julgar" (Descartes a Elisabeth, 18 outubro de 1645, AT V, p. 277). 
superficial dos textos cartesianos) de afirmar que as paixões não podem ser objetos da ciência cartesiana, a qual só trataria das coisas claras e distintas. Descartes considera seu Tratado sobre as paixões como sendo precisamente um tratado de ciência, isto é, um discurso cognitivo levado pelo esforço racional de conceber as coisas clara $e$ distintamente. Até porque a concepção cartesiana de ciência não consiste em dizer que só podemos conhecer as coisas que são claras e distintas (tais como as verdades eternas e, de modo geral, todos os conteúdos inatos da mente), mas que só podemos conhecer verdadeiramente aquilo que percebemos clara e distintamente.

Ora, embora aquilo que percebemos clara e distintamente sejam, em geral, as coisas que são elas próprias claras e distintas, Descartes reconhece expressamente, no entanto, que mesmo nas coisas obscuras e confusas podemos conceber algo clara e distintamente: podemos perceber, por exemplo, clara e distintamente, que temos certas ideias obscuras e confusas; do mesmo modo, podemos perceber clara e distintamente que sobre tais ideias obscuras e confusas não podemos fazer juízos sobre o valor objetivo delas. Podemos perceber, também, clara e distintamente que, se compararmos as ideias obscuras e confusas que temos sobre as coisas exteriores com a ideia clara e distinta que temos da extensão fornecida pela intuição intelectual, tais ideias não representam a verdadeira natureza exterior, que é desprovida de qualidades sensíveis (isso Descartes mostra no final da Meditação Sexta, bem como no primeiro e também segundo livro dos Princípios da Filosofia - só para citar alguns exemplos). Além disso, examinando com clareza e distinção as ideias obscuras e confusas, podemos perceber, clara e distintamente, lá no início da Sexta Meditação (uma vez em posse da ideia clara e distinta de Deus), que tais ideias possivelmente correspondem a uma realidade exterior, já que envolvem a faculdade de imaginação. Finalmente, na sequência disso, examinando os sentidos e confrontado com a ideia de um Deus veraz, somos levados a conceber clara e distintamente que existem corpos exteriores, que a nossa própria alma 
está substancialmente unida a um corpo (do qual, entretanto, ela é, por natureza, radicalmente distinta).

Observemos que todas as provas que Descartes começa a fazer na Meditação Sexta, não consistem apenas em equacionar ideias claras e distintas entre si, mas em utilizar-se delas para conceber o mais clara e distintamente as próprias ideias obscuras e confusas, que são imprescindíveis para a prova da existência de um mundo exterior e de nossa união com o corpo. Sem o exame claro e distinto das ideias obscuras e confusas não seria possível fazer essas provas.

Isso mostra também que, contrariamente ao que se poderia pensar, a união corpo e alma não é simplesmente uma experiência que temos pelas nossas sensações, mas ela é também realmente provada pelo entendimento. Este prova rigorosamente (segundo a ordem das razões) que a alma está necessariamente e intimamente unida a um corpo cuja natureza é radicalmente diferente da sua. O que a alma não prova é como é possível que duas naturezas assim distintas estejam unidas, mas, que elas estejam unidas, isso a alma prova, sim, na Meditação Sexta. E ela prova precisamente apelando para o exame das ideias obscuras e confusas: dado que eu experimento ideias que não podem provir de meu espírito (já que provei ser radicalmente distinto da extensão), elas, portanto, só podem provir de fora de mim. Ora, de duas uma: ou tais ideias vêm das próprias coisas que representam, ou vêm de uma causa mais eminente; dado, porém, que tenho inclinação natural para acreditar que provêm das próprias coisas que representam e visto, por outro lado, que Deus não me deu nenhuma outra faculdade para saber que não seria assim, então, se as coisas viessem de causas mais eminentes, Deus estaria me enganando. Ora, engano não é compatível com a natureza de Deus. E eu já provei verdadeiramente que Ele existe; logo as coisas provêm necessariamente das coisas que elas representam. Isso inclui afirmar que as ideias e sentimentos que tenho de um corpo que existe intimamente unidas a mim provêm necessariamente desse corpo.

Descartes, é verdade, nunca forneceu a prova de como é possível 
que duas substâncias assim distintas possam conviver, mas a prova de direito não invalida uma prova (uma demonstração rigorosa) do fato. Convém insistir: não estou afirmando que o simples fato é suficiente para se contrapor a ausência de uma prova de direito; estou dizendo, tal como o faz Gueroult, ${ }^{38}$ que o fato é logicamente provado, por argumentos necessários, embora, não se possa fornecer também uma prova de direito.

Todavia, se Descartes não pode explicar como é possível tal união, ele pode, no entanto, explicar qual é o funcionamento de tal união e isso ele efetivamente o faz no Tratado das Paixões. Quer dizer, ele não demonstra como é possível que a alma, sendo não-extensa, pode estar unida a um corpo extenso, no entanto, como ele já provou na Meditação Sexta, ela de fato está (já que é afetada por um corpo, tanto por sensações internas quanto externas). Ora, se a alma efetivamente está unida ao corpo, Descartes então chega à conclusão que ela só pode estar no cérebro (que, segundo os estudos de Descartes, é o órgão responsável pelos movimentos de todo o corpo e pela captação dos dados sensoriais). No cérebro, a glândula pineal apresenta uma série de características privilegiadas que levam Descartes a concluir que a alma só pode estar ali. Nesse local, Descartes, servindo-se de uma descrição neurofisiológica das representações mentais e tendo como veículo de ligação uma matéria muito sutil chamada "espíritos animais" (os impulsos nervosos), mostra como o corpo age sobre a alma e como esta age sobre aquele, embora nunca explique como é possível que a alma possa estar alojada no corpo.

Data de registro: $18 / 07 / 2011$

Data de aceite: 24/08/2011

${ }^{38}$ Descartes Selon L'Ordre des Raisons, Paris, Aubier, 1953, Vol. II, cap. XV. 